\title{
Comparative Analysis of the Compaction of Natural Offshore Sand and Cement Stabilized Offshore Sand for Road Construction
}

\author{
Owo Awajigbana Tugwell \\ Department of Civil Engineering, University of Nigeria, Nsukka, Nigeria \\ Email address: \\ awajigbana.owo.pg76722@unn.edu.ng

\section{To cite this article:} \\ Owo Awajigbana Tugwell. Comparative Analysis of the Compaction of Natural Offshore Sand and Cement Stabilized Offshore Sand for \\ Road Construction. Journal of Civil, Construction and Environmental Engineering. Vol. 6, No. 2, 2021, pp. 21-27. \\ doi: $10.11648 /$ j.jccee.20210602.11
}

Received: February 18, 2021; Accepted: March 3, 2021; Published: March 12, 2021

\begin{abstract}
This research concerned itself with the comparative analysis of compaction of natural offshore sand and cement stabilized offshore sand for road construction in swampy regions. Sieve analysis and compaction (moisture-density relationship) tests were conducted on the offshore sand sample to compare the compaction efforts of the two materials for road subbase filling. Based on the results of the tests carried out, the offshore sand sample was found to belong to the A-2 group and falls within Grading Zone 2. The results of dry density against cement content as well as optimum moisture content against cement content shows that compaction of the offshore sand is poor with values of maximum dry density and optimum moisture content obtained as $1.755 \mathrm{~g} / \mathrm{cm} 3$ and $11.67 \%$ respectively. After $4 \%$ Cement Content stabilization, the values increased to $1.935 \mathrm{~g} / \mathrm{cm} 3$ and $12.21 \%$ respectively. At $6 \%$ Cement Content stabilization, the value of Maximum Dry Density increased to $1.948 \mathrm{~g} / \mathrm{cm} 3$ while the Optimum Moisture Content dropped to $8.77 \%$. At $8 \%$ cement content stabilization, the values obtained were $1.967 \mathrm{~g} / \mathrm{cm} 3$ for maximum dry density and $10.40 \%$ for optimum moisture content. At $10 \%$ cement content, the results were $1.982 \mathrm{~g} / \mathrm{cm} 3$ for maximum dry density and $12.25 \%$ for optimum moisture content. Upon increasing cement content to $12 \%$, the values obtained became $2.027 \mathrm{~g} / \mathrm{cm} 3$ for maximum dry density and $9.76 \%$ for optimum moisture content. It follows therefore that increasing cement contents yielded increase in compaction of the offshore sand sample. This investigation concludes that cement can be used to stabilize offshore sand to improve its engineering property of compaction for use as subbase material for construction of road in swampy regions.
\end{abstract}

Keywords: Compaction, Maximum Dry Density, Optimum Moisture Content, Offshore Sand, Cement

\section{Introduction}

Road design and construction are as old as man found it necessary to move from one location to another. Biblical references to roads and paths are numerous and can be found in many chapters of the bible. It is believed animal trails were first pathways. Human travelers used rough paths in 10,000 BC. The world's oldest known paved road was built sometime between $2600 \mathrm{BC}$ and $2200 \mathrm{BC}$ in Egypt. Previously, it was faster to embark on journeys by river than road especially because of high cost of road transportation, and total number of persons conveyed by river badges were more. In 312 BC, Roman Empire built 29 major roads within Europe and North Africa spanning about 78 kilometers to support its military campaign.

It has been observed that there is a large deposit of offshore sand as a result of continuous weathering of the Atlantic Ocean by Ikuru Town, Andoni Local Government Area of Rivers State. Over the years, local building developers within the town are not using the offshore sand for building construction works stating it has high salt content in it.

Recently, Rivers State Government awarded the construction of the Ogoni - Andoni - Opobo Unity Road and Bridges contract (a $44 \mathrm{~km}$ road network through the swamps) to Messrs Raffoul Nigeria Limited. The road contractor upon discovering the offshore sand near the construction sites opted to haul it for road subbase filling considering cost- 
benefit implications and reduction in construction duration for the project.

It became necessary to study the engineering properties of the offshore sand and how to improve on them using cement as a stabilizing agent to enhance its suitability for filling as a road subbase material.

The objectives of this research work include the following:

To carry out the particle size analysis of the offshore sand;

To determine the moisture-density relationship and CBR of the offshore sand; and

To use cement for the stabilization of the offshore sand.

Although there is little or no previous work is done in this regard in the swampy regions in Nigeria, enormous research work has been done elsewhere in the world, new approaches have been discovered due to others research' efforts with a better and cost-effective method of sand cement stabilization of road sub-base material in flexible pavements.

Chinemere Ogbonnay posited that bituminous stabilization of fine sand is widely adopted in regions where cohesionless soils abound [2].

Bolarinwa suggested that soils that cannot be used for engineering purposes without stabilization are problematic and so affect performance, construction cost, and maintenance of road infrastructures in the Nigeria [1].

Jones et al. found that rehabilitation of road using foamed bitumen is successful because of its compatibility, enhancing construction speed [3].

Paul et al. suggested that knowledge of stabilization is needed to predict effects of land use changes on stability of soil in the tropics [9].

Harris et al. worked on road base stabilization using cement and bitumen and asserted that cement stabilization of soils differs from bitumen stabilization in that bitumen provides waterproofing stabilization; while cement offers resilient high strength surface to receive additional road base materials [5].

Martin et al. worked on foam bitumen stabilization with $2 \%$ of cement and $3.5 \%$ of bitumen foam. Their work found that rehabilitating road with foamed bitumen is thriving because of compatibility with aggregates [7].

Marandi et al. researched on bitumen-cement stabilized road in indirect tensile strength method where concrete and bitumen emulsion were used as stabilizing agents [6].

Ramanujam et al. developed mix for foamed stabilized bitumen [10].

Marto et al. came up with conclusion that TX-85 and SH85 traditional additives for stabilization contribute to denser soil fabric [8].

Yang et al. carried out an investigation into the effects of aging tests on chemical sand-stabilization [11].

Nikraz researched on bitumen-cement stabilized road using indirect tensile strength method. In this study, concrete and bitumen emulsion were used as stabilizing agents [4].

Yuehuan et al. worked on foamed bitumen stabilization for Australian roads [12].

Choi et al. worked on the assessment of field compaction of aggregate base materials for permeable pavements based on plate load tests to encourage these hydrologic functions of permeable pavements, their structure should contain connected pores [13].

Umashankar et al. carried out investigation on the compaction quality control of pavement layers [14].

Walubita et al. established a comprehensive data storage system for better calibration of the mechanical-empirical design and rehabilitation of flexible pavements [15].

\section{Materials and Method}

In the experimental investigation, offshore sand from the Atlantic ocean, Ikuru Town, Andoni Local Government Area of Rivers State, Nigeria was chosen as a subbase material for flexible road pavement construction through the swampy region; its Particle Size Analysis and Compaction tests were conducted on the offshore sand sample, and cement stabilization was done for $4 \%, 6 \%, 85,8 \%, 10 \%$, and $12 \%$ cement contents.

Particle Size Distribution

The sand sample is passed through standard sieve sizes to determine its grading zone in the Casagrande chart. About $300 \mathrm{~g}$ of a dried sample of the soil is passed through sieve no. $200(0.075 \mathrm{~mm})$. Quantity retained is weighed and the percentage retained as well as percentage passing are calculated.

Recall, for granular materials (cohesionless) soils, less than $35 \%$ of the materials will pass sieve no $200(0.075 \mathrm{~mm})$.

Compaction

The standard Proctor test was adopted for this study. This involves compacting air-dried soil sample into a cylindrical mold. With the standard Proctor test, a $50 \mathrm{~mm}$ diameter, $2.5 \mathrm{~kg}$ metal rammer was dropped through $300 \mathrm{~mm}$ for 27 blows onto each of the three layers of soil in the mold. The mass of the soil was determined and its bulk and dry densities calculated as shown in equations 3 and 4, respectively. The process was repeated until the mass of the soil in the mold was less than the preceding measurement. The test procedure is fully described in BS 1377-4-Soil Compaction.

Compaction Procedure

Obtained about $2.5 \mathrm{~kg}$ a representative sample of the air dry cohesionless soil without cement and with different percentages of cement.

Water was added to bring the sample to within about $12-14 \%$ of the estimated optimum water content and mixed thoroughly.

The mold and base plate were cleaned and dried, and lightly greased.

the mold was weighed with the base plate and the collar Mold was then measured to determine the volume.

The soil was mixed thoroughly; kept in an air-tight container, and divided the processed soil into 3 parts.

The collar was attached to the mold placed on a solid base.

The soil was compacted in the mold using standard compaction effort.

One-third of the quantity was extracted, compacted with 25 blows of the rammer. 
The same procedure was repeated for the second layer and third layer.

The collar was removed and the compacted mixture trimmed even with the top of the mold with the steel straight edge.

The base plate was cleaned and weight of the mold and cylinder of soil was taken in reading.

The soil was then extracted from the mold, split, and obtained a sample to test for water content.

This sample was placed on a balance, the weight of the sample with the container was taken, and the sample was placed in the oven to dry.

Water was added to increase the water content by about $2 \%$ to a fresh portion of the processed soil and repeated the steps from step 6 to step 14 .

The procedure in steps 6-14 was repeated to get a total of at least four to five trials so that the weights $\mathrm{W}_{1}, \mathrm{~W}_{2}, \mathrm{~W}_{3}$ and $\mathrm{W}_{4}$ and the corresponding water contents $\omega_{1}, \omega_{2}, \omega_{3}, \omega_{4}$, and $\omega_{5}$ were obtained. The range of water content covered with the trails was such that the OMC lies between $\omega_{2}$ and $\omega_{3}$.

A graph was plotted with the water content on the $\mathrm{x}$-axis and the dry density on the y-axis. The experimental points are joined by a smooth curve, which is known as the compaction curve.

\section{Results}

The result of sieve analysis in Figure 1 shows that $2.244 \%$ of sample was retained on sieve no $10(2.00 \mathrm{~mm}) ; 49.872 \%$ passed on sieve no $40(0.425 \mathrm{~mm})$ and stayed within the area designated on the Casagrande Chart as A-2.

It also shows sample falls within Grading Zone 2 according to BS 882:1973 and ASTM standard C33-78 grading requirements for fine aggregate and represents a gap graded medium sand generally suitable for 1:2 fine to coarse aggregate mix

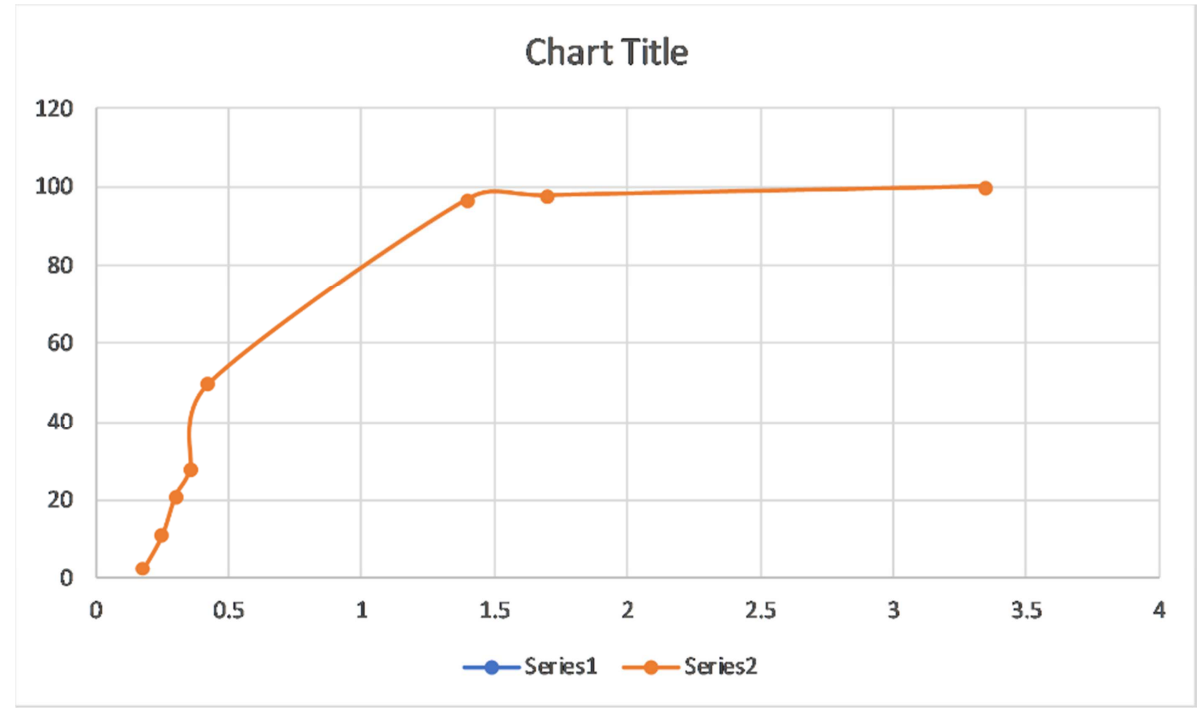

Figure 1. Sieve analysis of the offshore Sand Sample.

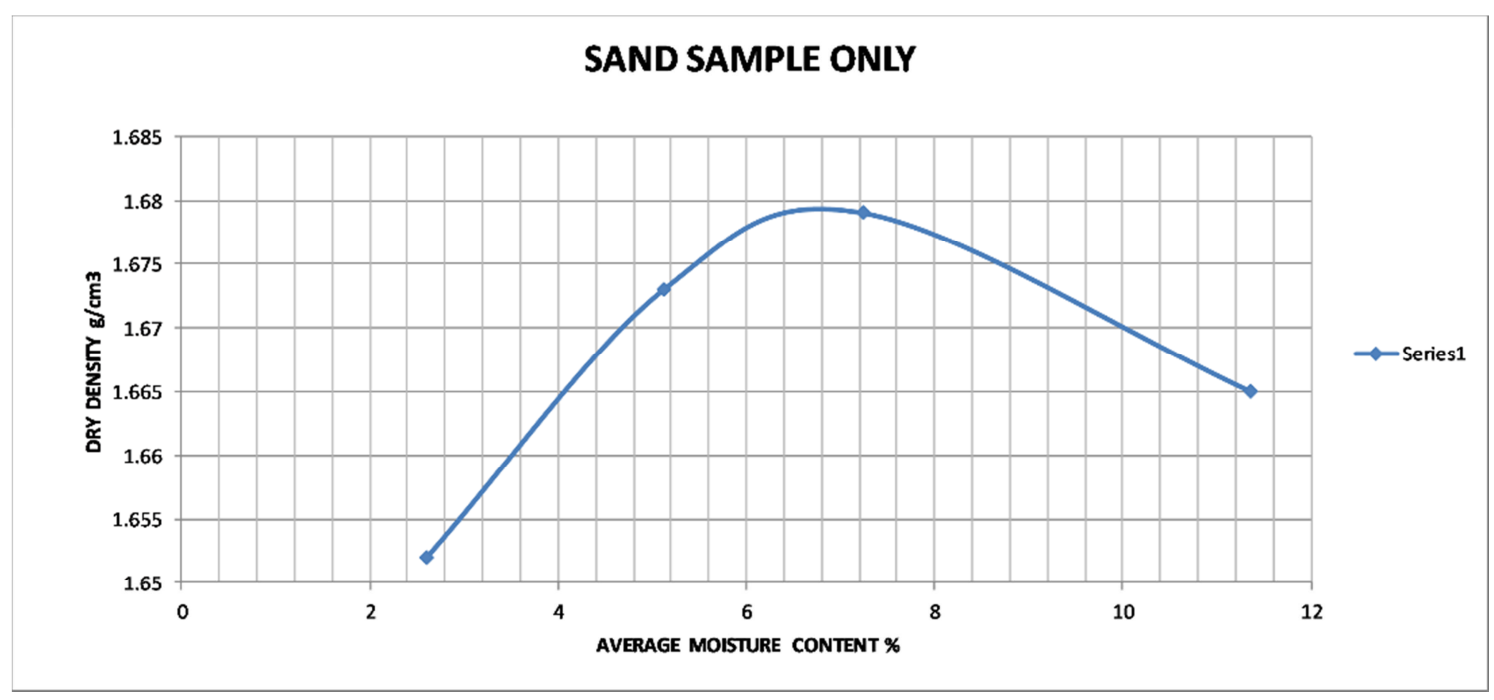

Figure 2. Determination of compaction of natural offshore sand before stabilization. 


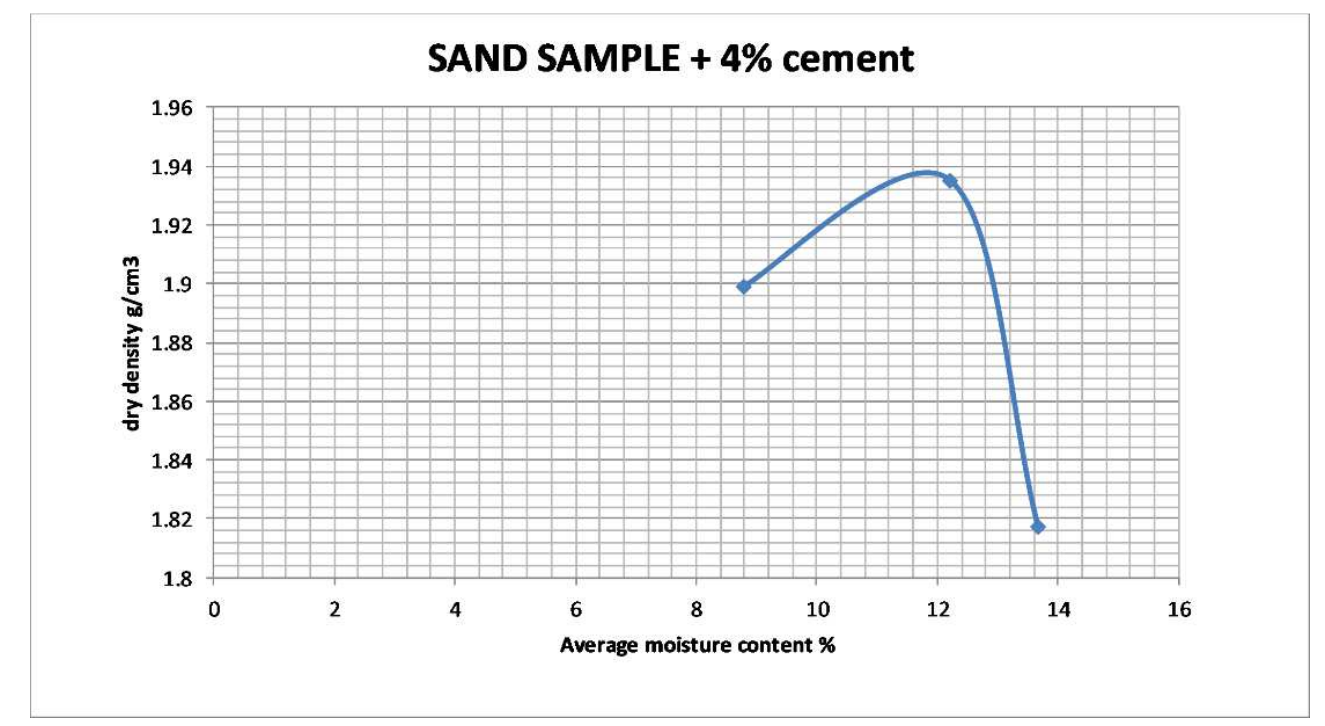

Figure 3. Determination of compaction at $4 \%$ cement stabilization.

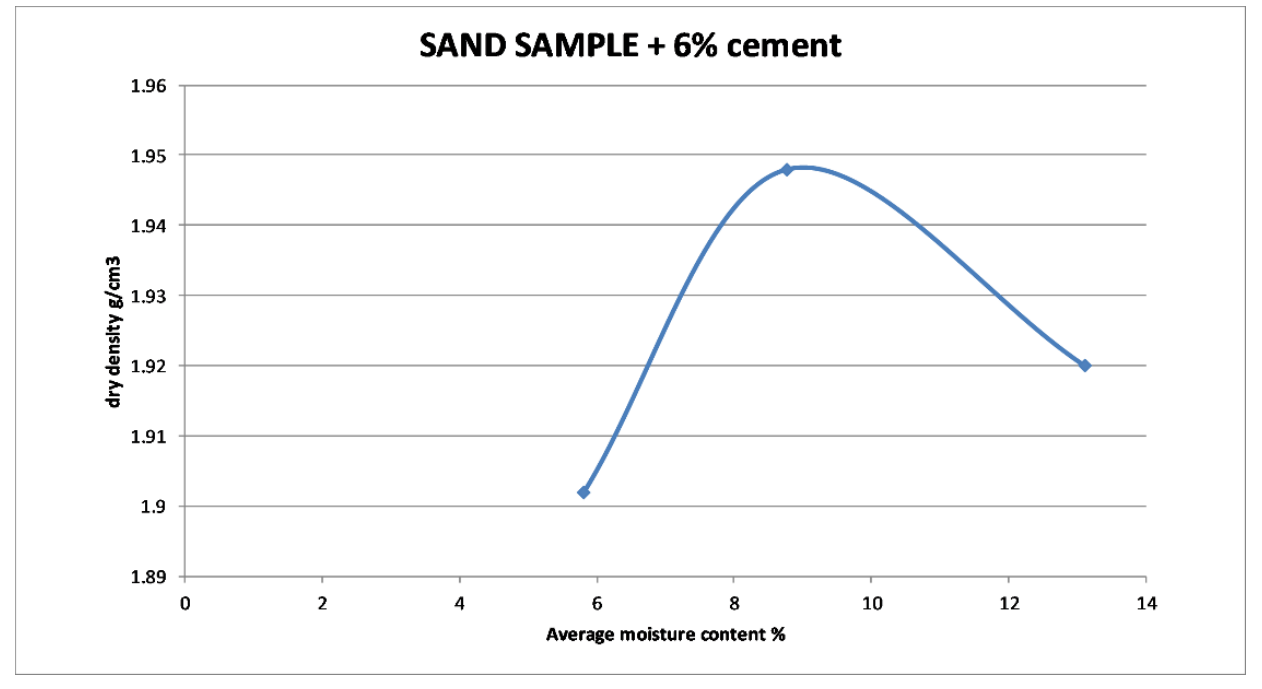

Figure 4. Compaction curve at $6 \%$ cement stabilization.

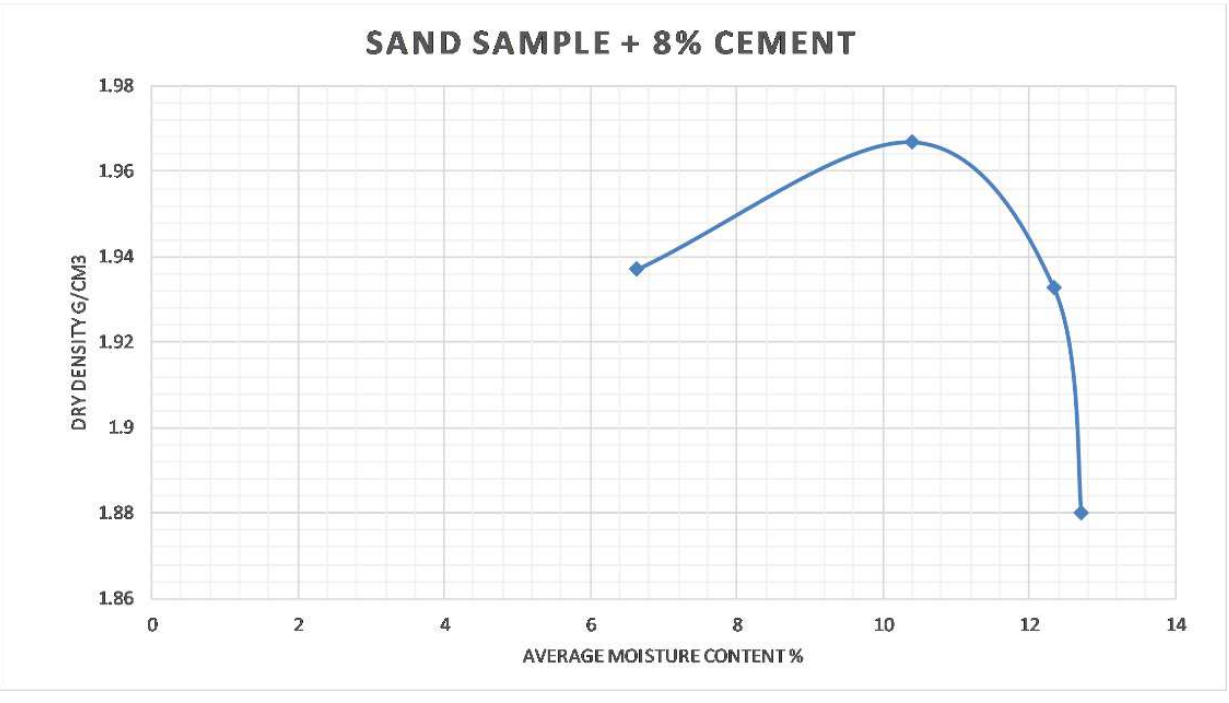

Figure 5. Compaction curve at $8 \%$ cement stabilization. 


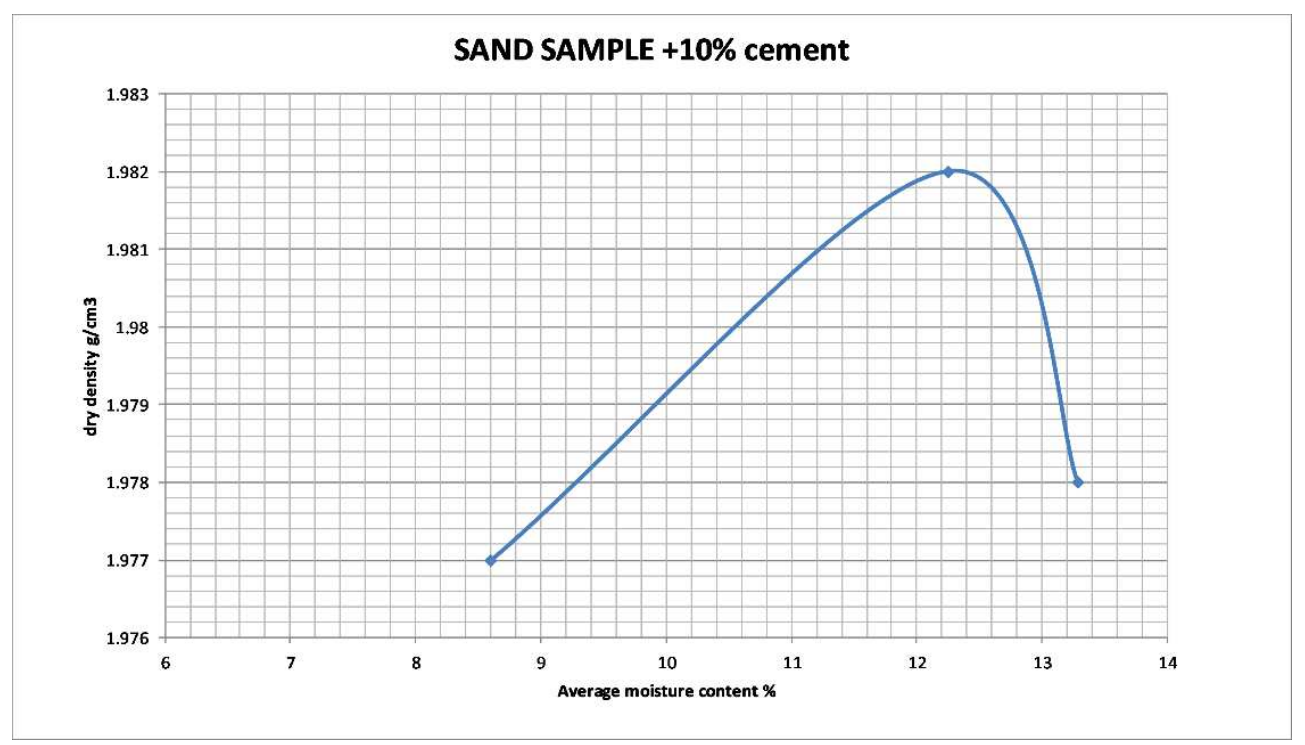

Figure 6. Compaction at 10\% cement stabilization.

\section{SAND SAMPLE + 12\% CEMENT}

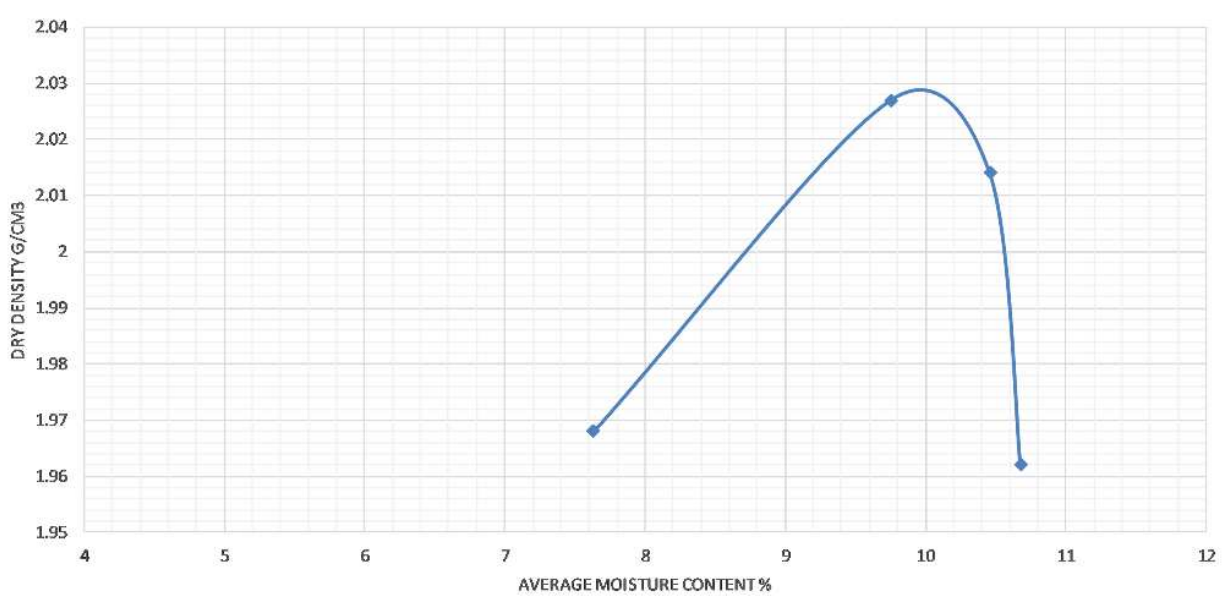

Figure 7. Compaction at $12 \%$ cement stabilization.

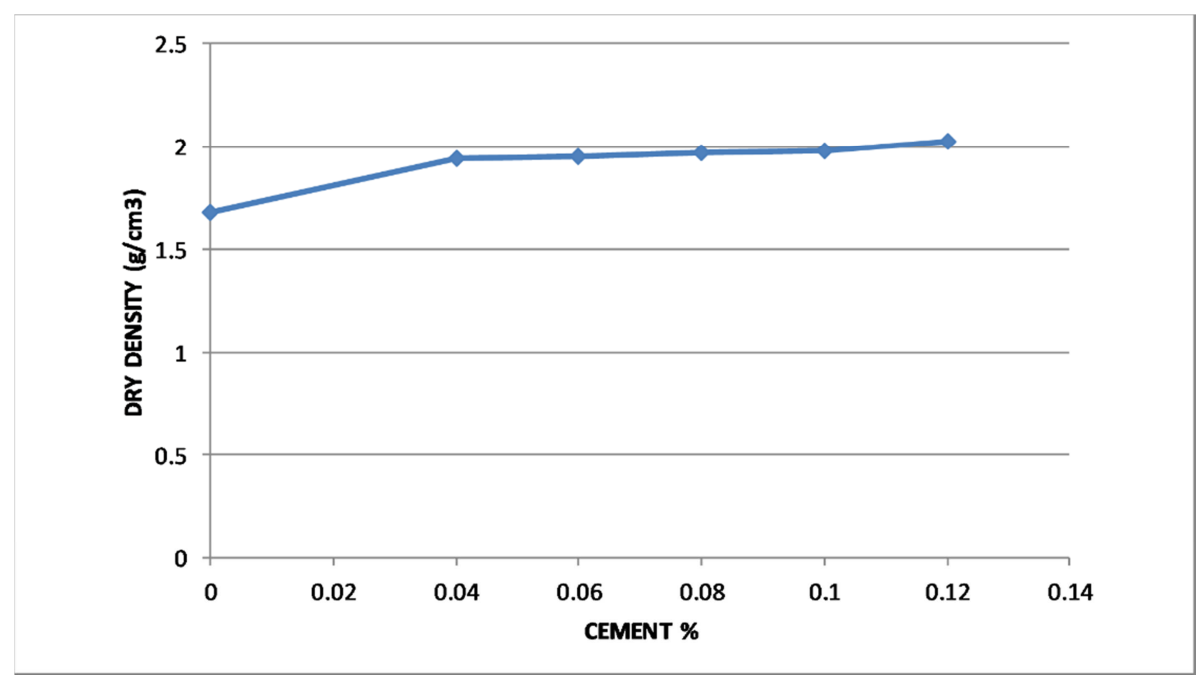

Figure 8. Graph of Maximum Dry Density against Cement Content. 


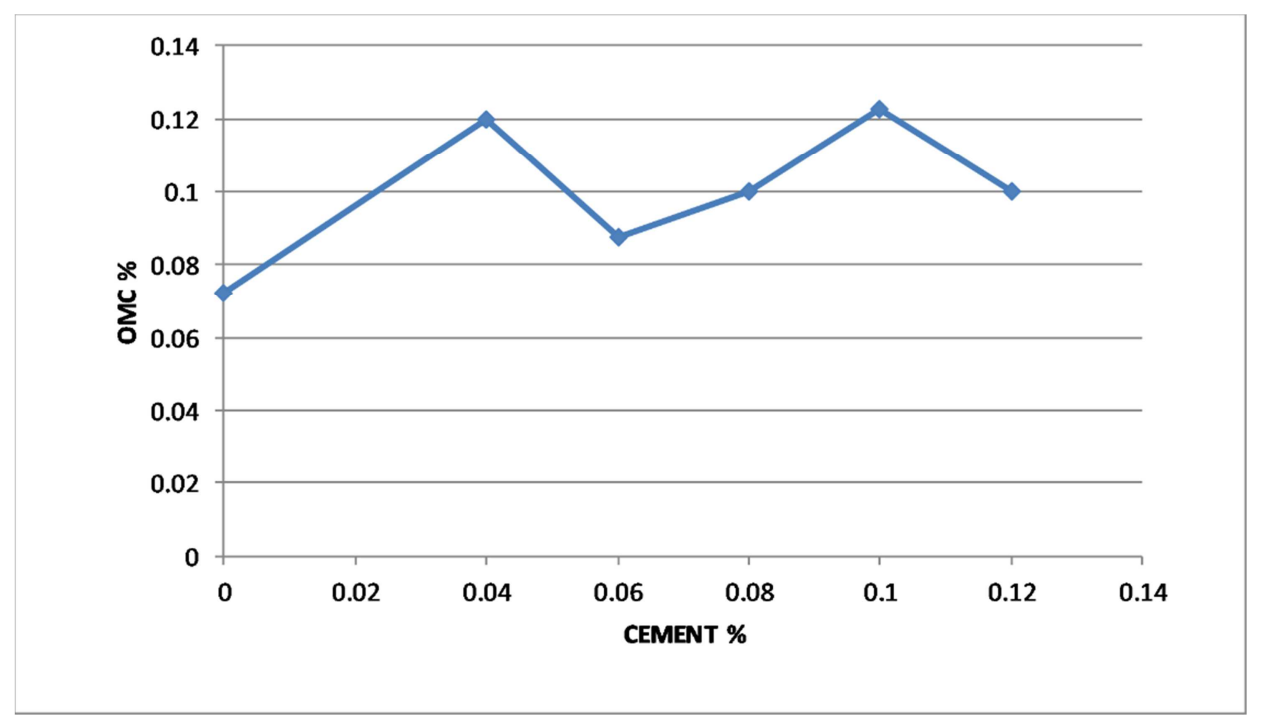

Figure 9. Graph of Optimum Moisture Content against Cement Content.

\section{Discussion}

The results compaction of natural offshore sand is presented in figure 2. It is seen that compaction of the offshore sand is poor with values of Maximum Dry Density and Optimum Moisture Content obtained as $1.755 \mathrm{~g} / \mathrm{cm} 3$ and $11.67 \%$ respectively; while the results of compaction of natural offshore sand plus cement stabilization at $4 \%, 6 \%$, $8 \%, 10 \%$, and $12 \%$ cement contents are presented in figures 3, 4, 5, 6 and 7 respectively. After 4\% Cement Content stabilization, the values increased to $1.935 \mathrm{~g} / \mathrm{cm} 3$ and $12.21 \%$ respectively. At $6 \%$ Cement Content stabilization, the value of Maximum Dry Density increased to $1.948 \mathrm{~g} / \mathrm{cm} 3$ while the Optimum Moisture Content dropped to $8.77 \%$. At $8 \%$ Cement Content stabilization, the values obtained were $1.967 \mathrm{~g} / \mathrm{cm} 3$ for Maximum Dry Density and $10.40 \%$ for Optimum Moisture Content. At 10\% Cement Content, the results were $1.982 \mathrm{~g} / \mathrm{cm} 3$ for Maximum Dry Density and $12.25 \%$ for Optimum Moisture Content. Upon increasing Cement Content to $12 \%$, the values obtained became $2.027 \mathrm{~g} / \mathrm{cm} 3$ for Maximum Dry Density and $9.76 \%$ for Optimum Moisture Content.

Figures 8 and 9 show summary of dry density against cement content and optimum water content against cement content at a glance.

It follows therefore that increasing cement contents yielded increased compaction of the offshore sand sample; while the optimum moisture content dropped at $6 \%$ and increased at $8 \%$ and $10 \%$ before dropping at $12 \%$ cement contents. Compaction at $10 \%$ cement and above showed sufficient strengths for subbase in comparison with Waliur Rahman and Gurmel Ghataora of Department of Civil Engineering, University of Birmingham, UK.

For sand to be used as subbase material, the Federal Ministry of Works (1997) recommends that the value of MDD should be between 1.7 and $2.1 \mathrm{~kg} / \mathrm{m} 3$ while OMC values should fall between 7 and $15 \%$. The results for the offshore sand after stabilized with cement fall within these ranges and hence satisfy the recommended limits for road construction.

\section{Conclusion}

From this investigation, the following conclusions are drawn:

Cement can be used to stabilize offshore sand to improve its engineering properties for use as a subbase material for the construction of roads in swampy regions;

Increasing cement contents during stabilization of the offshore sand sample yielded an increase in compaction. it is seen that compaction of the offshore sand was poor with values of Maximum Dry Density and Optimum Moisture Content obtained as $1.755 \mathrm{~g} / \mathrm{cm}^{3}$ and $11.67 \%$ respectively. After 4\% cement content stabilization, the values increased to $1.935 \mathrm{~g} / \mathrm{cm}^{3}$ and $12.21 \%$ respectively. At $6 \%$ cement content stabilization, the Maximum Dry Density increased $1.948 \mathrm{~g} / \mathrm{cm}^{3}$ and Optimum Moisture Content dropped to $8.77 \%$. At $8 \%$ cement content stabilization, the MDD and OPC values obtained were $1.967 \mathrm{~g} / \mathrm{cm}^{3}$ and $10.40 \%$ respectively. At 10\% cement content, the MDD and OPC values increased to $1.982 \mathrm{~g} / \mathrm{cm}^{3}$ and $12.25 \%$ respectively; and at $12 \%$ cement content, the Maximum Dry Density obtained rose to $2.027 \mathrm{~g} / \mathrm{cm}^{3}$ and Optimum Moisture Content dropped to $9.76 \%$.

\section{Recommendations}

From the results of this investigation, the following recommendations are made:

The use of cement to stabilize poor offshore sand subbase materials for road construction in the swampy region should be encouraged.

Cost-Benefit analysis could be done on this material in comparison with sharp sand from other sources. The material with the best cost - benefit value should be given preference. 


\section{References}

[1] Bolarinwa, A. (2009). Geotechnical Properties of Nigerian Soils.

[2] ChinemereOgbonnaya (2014). Bituminous Stabilization of clay soils for road construction.

[3] D. Jones, A. Rahim, S. Saadeh, and J. THarvey (2012), Guidelines for the Stabilization of Subgrade Soilsin California, Guideline: UCPRC-2010-01.

[4] H. R. NIkraz (2012). Bitumen - Cement stabilized layer in Pavement Construction.

[5] Harris, V. A. P, Hitch L. S and J. M Jowett (1983), Bituminous Stabilization of Fine Sands.

[6] Marandi S. M and Safapour P (2012). Laboratory study on the use of bitumen emulsion in a gravel road.

[7] Martin et al. (2009). Foamed Bitumen Stabilization.

[8] Marto, A.; Latifi, N.; Eisazadeh, A. (2014). Effect of nontraditional additives on engineering and microstructural characteristics of laterite soil. Arab. J. Sci. Eng. 39: 69496958.

[9] Paul et al. (2011). Laboratory performance of Asphalt emulsion treated base.

[10] Ramanujan and Jones (2008) Design mix for foamed stabilized bitumen.

[11] Yang, J.; Wang, F.; Fang, L.; Tan, T. (2007). The effects of aging tests on a novel chemical sand-fixing agentPolyaspartic acid. Compos. Sci. Technol. 67: 2160-2164.

[12] Yuehuan et al (2010). A preliminary study on foamed Bitumen stabilization for Western Australian pavements.

[13] Choi, Y.; Ahn, D.; Nguyen, T. H.; Ahn, J. Assessment of field compaction of aggregate base materials for permeable pavements based on plate load tests. Sustainability 2018, 10, 3817.

[14] Umashankar, B.; Hariprasad, C.; Kumar, G. T. Compaction quality control of pavement layers using LWD. J. Mater. Civ. Eng. 2016, 28, 04015111.

[15] Walubita, L. F.; Lee, S. I.; Abu-Farsakh, M.; Scullion, T.; Nazarian, S.; Abdallah, I. Texas Flexible Pavements and Overlays, Year 5 Report. Complete Data Documentation; FHWA/TX-15/0-6658-3; Texas Department of Transportation: College Station, TX, USA, 2017. 